\title{
Study of the Phase Transformations in Ni-Ti Based Shape Memory Alloys
}

\author{
L. Jordan*,**,***, M. Chandrasekaran****, M. Masse*,** and G. Bouquet***** \\ * Laboratoire de Métallurgie Structurale, ENSCP, 11 rue Pierre et Marie Curie, 75231 Paris cedex 05, \\ France \\ ** Centre d'Etude de Chimie Métallurgique, CNRS, 15 rue G. Urbain, 94407 Vitry-sur-Seine, France \\ *** Faculté de Chirurgie Dentaire, 5 rue Garancière, 75006 Paris, France \\ **** AMT n.v. Industrieweg, 43, B-3540 Herk-de-Stad, Belgium \\ ***** GEMH Université du Havre, Quai Frissard, BP. 265, 76055 Le Havre cedex, France
}

\begin{abstract}
Structural changes with cooling and heating of Ni-Ti alloys involve three phases : austenite, R-phase and martensite. The corresponding transformation sequences are often studied by techniques such as differential scanning calorimetry and internal friction. Structural transformation between any two phases is identified in these measurements by a peak in the studied property versus temperature plot. On this basis, the evidence of two transformations, austenite $\rightarrow$ R-phase and R-phase $\rightarrow$ martensite, have been established in the literature. In spite of exhibiting these two transitions on cooling, the reverse transformation from martensite, on heating, can be associated with one or two peaks. The exact interpretation of this behaviour thus poses an open question. This is attended to in this communication and the possible transformation sequences will be discussed with qualitative model. The data for the present investigation have been obtained on $\mathrm{Ni}_{50} \mathrm{Ti}_{50}$ and $\mathrm{Ni}_{47} \mathrm{Ti}_{50} \mathrm{CO}_{3}$ alloys.
\end{abstract}

\section{INTRODUCTION}

Previous studies by differential scanning calorimetry (DSC) [1] and internal friction (I. F.) measurements [2], on Ni-Ti shape memory alloys, have shown that stable transformation temperatures are obtained only after about 20 thermal cycles, for a specimen initially annealed at $700^{\circ} \mathrm{C}$. In Ni-Ti alloys, the structural transformation sequence on cooling is : Austenite $\rightarrow \mathrm{R}$-phase $\rightarrow$ Martensite. But, on heating the retransformation does not follow the inverse sequence. The present work concerns the variation in the results obtained on heating Ni-Ti based alloys and their interpretation. To this end, DSC, internal friction and X-ray diffraction results are reported and discussed.

\section{EXPERIMENTAL}

Equiatomic NiTi and 47 at $\% \mathrm{Ni} \mathrm{-} 50$ at\% $\mathrm{Ti}-3$ at \% Co alloys were prepared by melting pure metals in an induction furnace. The ingots $\left(\varnothing 16 \mathrm{~mm}, 40 \mathrm{~mm}\right.$ long) were hot rolled at $700^{\circ} \mathrm{C}$ to $1 \mathrm{~mm}$ thickness, after which the material was cold rolled with intermediate annealing treatments to reach a thickness of $0.5 \mathrm{~mm}$. Samples $0.5 \times 8 \times 70 \mathrm{~mm}^{3}$ and discs samples $(5 \mathrm{~mm} \times 1 \mathrm{~mm})$ were cut from this sheet. They were then annealed in vacuum $\left(10^{-5} \mathrm{~Pa}\right)$ at $700^{\circ} \mathrm{C}$ for 10 hours and slowly cooled in the furnace. This last thermal treatment was used as the reference structural state. Then the specimens were subjected to 20 thermal cycles. Subsequent experiments on the samples were carried out as follows

- DSC - a Mettler 30/TA 4000 was used at heating / cooling rate of $5^{\circ} \mathrm{C} / \mathrm{min}$.

- Internal friction measurements - Automatized inverted pendulum oscillating at a frequency of $1 \mathrm{hz}$ was used in conjunction with heating / cooling rate of $20^{\circ} \mathrm{C} /$ hour and a deformation amplitude of $10^{-5}$.

- XRD - A Philips.diffractometer $\left(\mathrm{Cu} \mathrm{K \alpha}, 1^{\circ} \theta / \mathrm{mn}\right)$ with a temperature attachment was used to detect the phases present at various temperatures.

Part of the Ni-Ti-Co alloy was also melt spun under a helium atmosphere onto a copper wheel. 

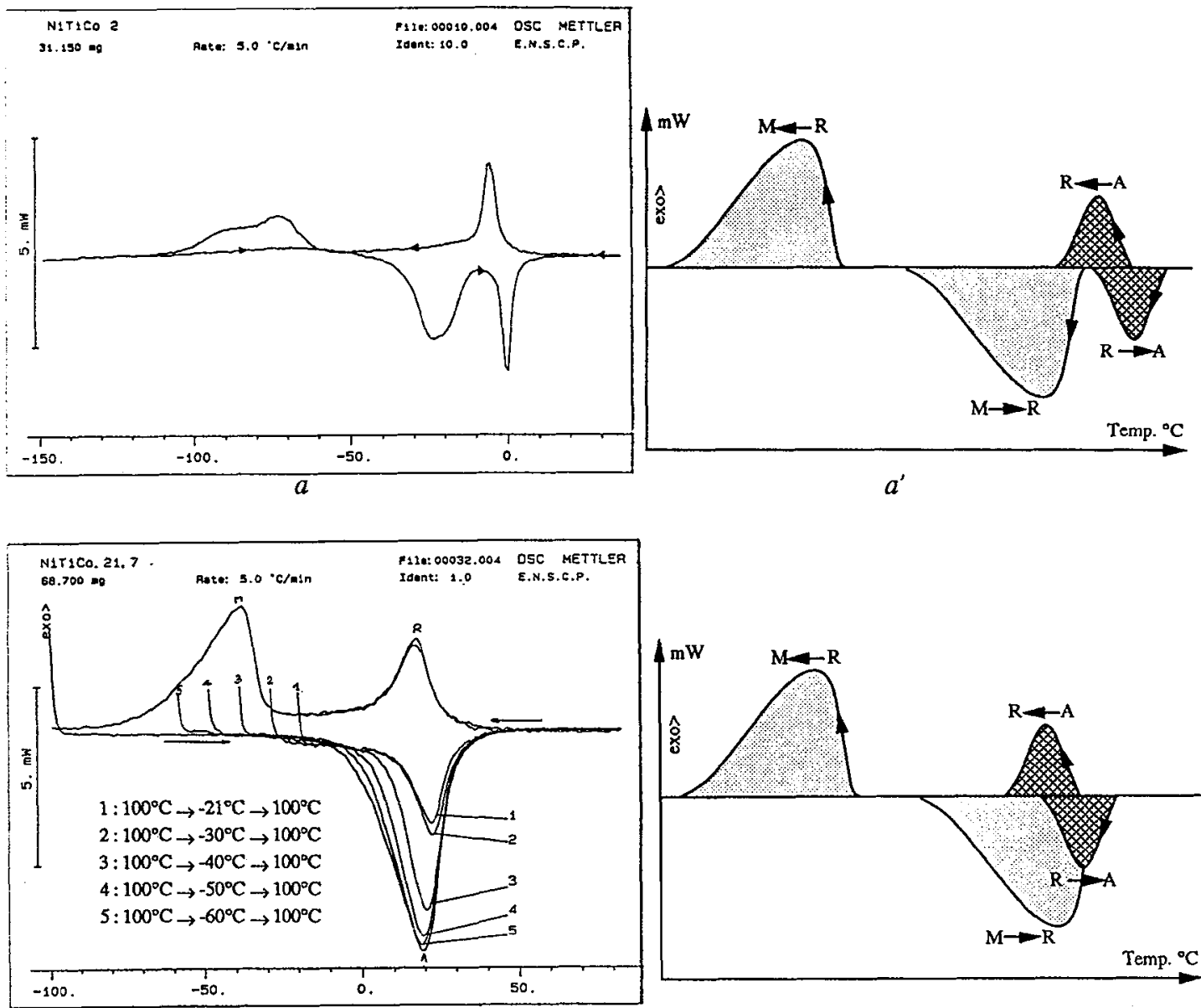

$b$

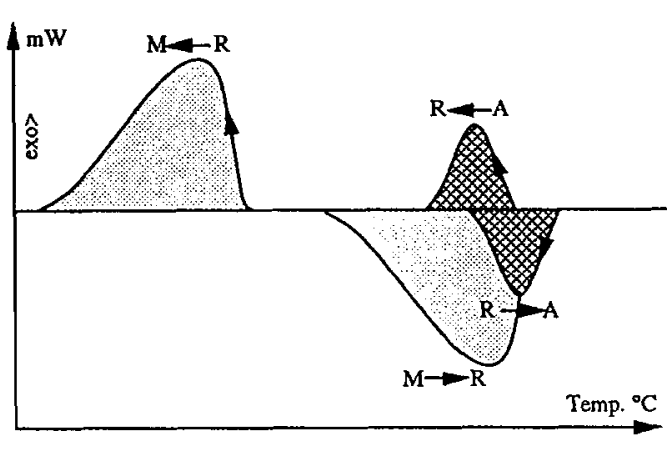

$b^{\prime}$

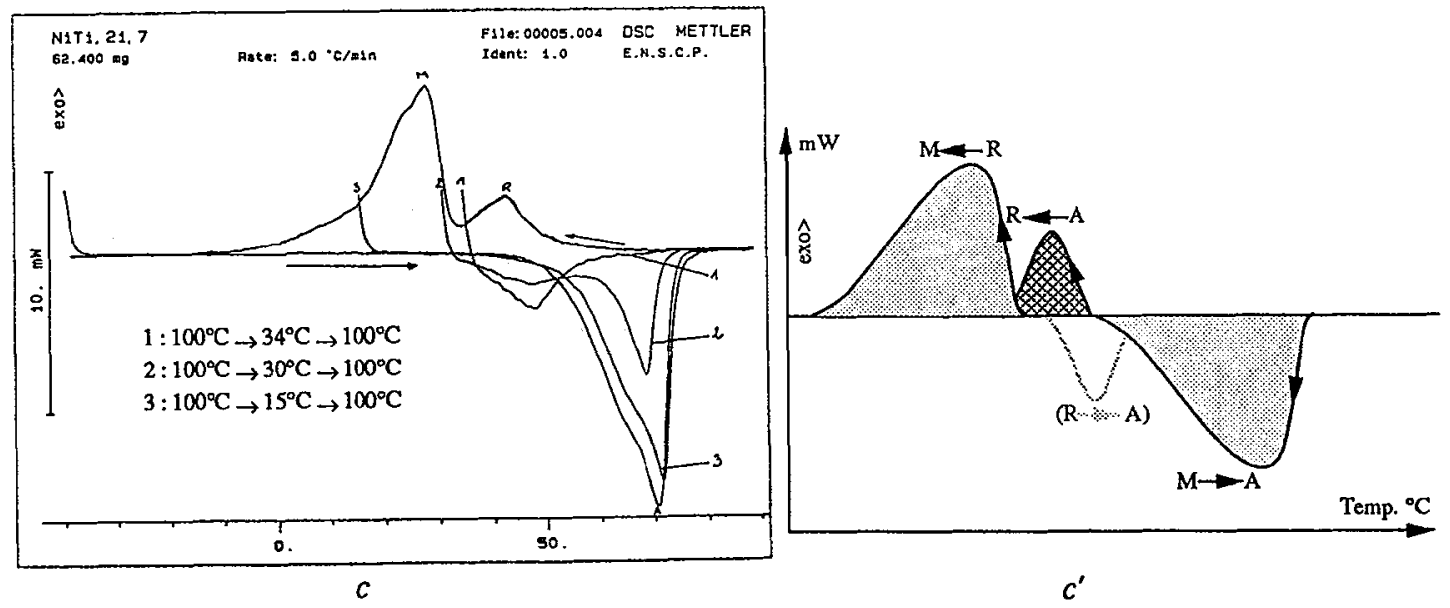

Figures $1 a, b$ and $c: D S C$ thermograms obtained using complete and partial thermal cycling.

Fig. la : Ni-Ti-Co rapidly solidified. Fig.lb : Ni-Ti-Co. Fig. Ic: NiTi.

Figures $1 a^{\prime}, b^{\prime}$ and $c^{\prime}$ : Structural evolution versus temperature modelling of Ni-Ti alloys. Fig. $1 a^{\prime}$ and $1 b^{\prime}$ : Ni-Ti-Co. Fig. $1 c^{\prime}:$ NiTi. 


\section{RESULTS}

\subsection{DSC}

In the case of the bulk material of either alloy, two peaks are obtained for the 21 st cycle cooling cycle. They correspond to the Austenite $\rightarrow$ R-phase and R-phase $\rightarrow$ Martensite transformations [3-4]. The peaks observed in Ni-Ti-Co may be seen to be farther apart than the peaks in the NiTi alloy. In either specimen, on heating only a single peak is detected. On the other hand, the melt spun Ni-Ti-Co exhibits two peaks both on cooling and on heating ( $A \leftrightarrow R$ and $R \leftrightarrow M$ ), as also an absence of temperature shifts of these peaks with cycling (Fig. 1a).

For a better understanding of the retransformation behaviour, heating cycles were recorded from the bulk materials after incomplete cooling cycles. A single peak appears on heating Ni-Ti-Co alloys under such conditions, independent of the temperature reached in the cooling cycle. Only the area of this peak increases with a lower temperature reached in the cooling cycle along with a concurrent displacement of the peak to lower temperatures (Fig. 1b). In NiTi, however, a peak which would correpond to the $\mathrm{R} \rightarrow \mathrm{A}$ transformation appears on heating after the first incomplete cycle (Fig. 1c). With lower temperatures reached in subsequent cycles ( 2 and 3 some martensite is generated), this peak gives way to the larger complete cycle peak. Again, there is a displacement of the peak temperature to lower values in response to a lower temperature reached in the cooling cycle.

\subsection{Internal Friction}

Two peaks on cooling, corresponding to Austenite $\rightarrow \mathrm{R}$ and $\mathrm{R} \rightarrow$ Martensite, are again observed with the Ni-Ti-Co alloy (Fig. 2a). The former is associated with a prominent decrease in the shear modulus [5]. On heating, a single non-symmetric peak is observed, again with a noticeable decrease in the modulus at the shoulder of the peaks.

In the case of $\mathrm{Ni}$-Ti alloy (Fig. 2b), a single peak with a shoulder is observed on cooling. The large decrease in modulus accompanying the shoulder is characteristic of the Austenite $\rightarrow R$ phase transformation. On heating, a single relatively symmetrical peak without the modulus decrease just mentioned is observed.

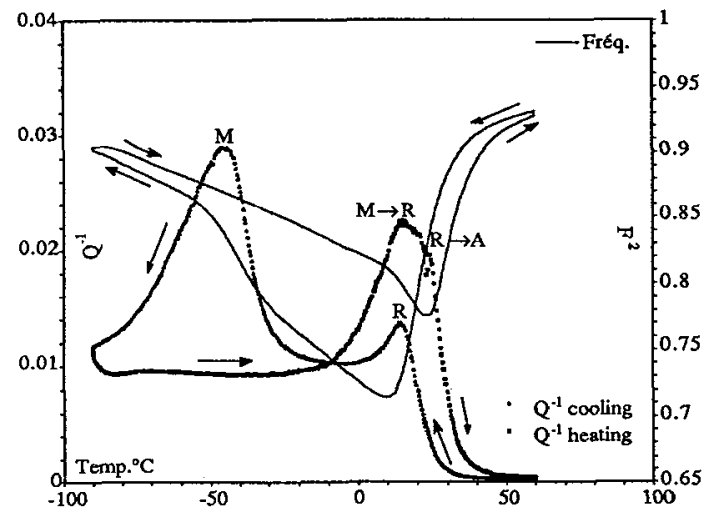

Figure $2 a:$ Internal friction and modulus evolutions of Ni-Ti-Co (21 st thermal cycle).

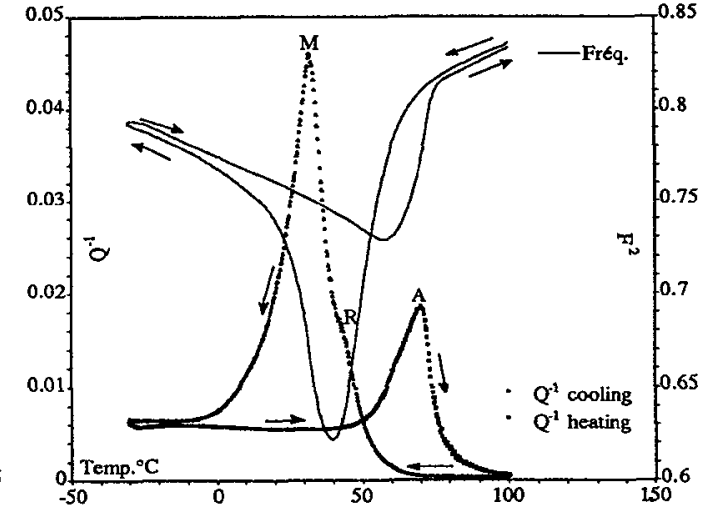

Figure $2 b$ : Internal friction and modulus evolutions of NiTi (21 $1^{\text {st }}$ thermal cycle).

\subsection{X-Ray Diffraction}

Three spectra corresponding to the three different phases have been obtained (Fig. 3). At $80^{\circ} \mathrm{C}$, the alloy is fully austenitic, characterised by two principal peaks (Table 1). At $-100^{\circ} \mathrm{C}$, it is fully martensitic (Table 2). At $-20^{\circ} \mathrm{C}$, we have the R-phase, characterized by the doubling of (110) and (211) austenite peaks and by three new peaks between 35 and $38^{\circ} \theta$ (Table 3, R-phase has a trigonal lattice with space group $P \overline{3} 1 \mathrm{~m}[6]: a_{R}=0,7348 \mathrm{~nm}$ et $c_{R}=0,5278 \mathrm{~nm}$ ). 


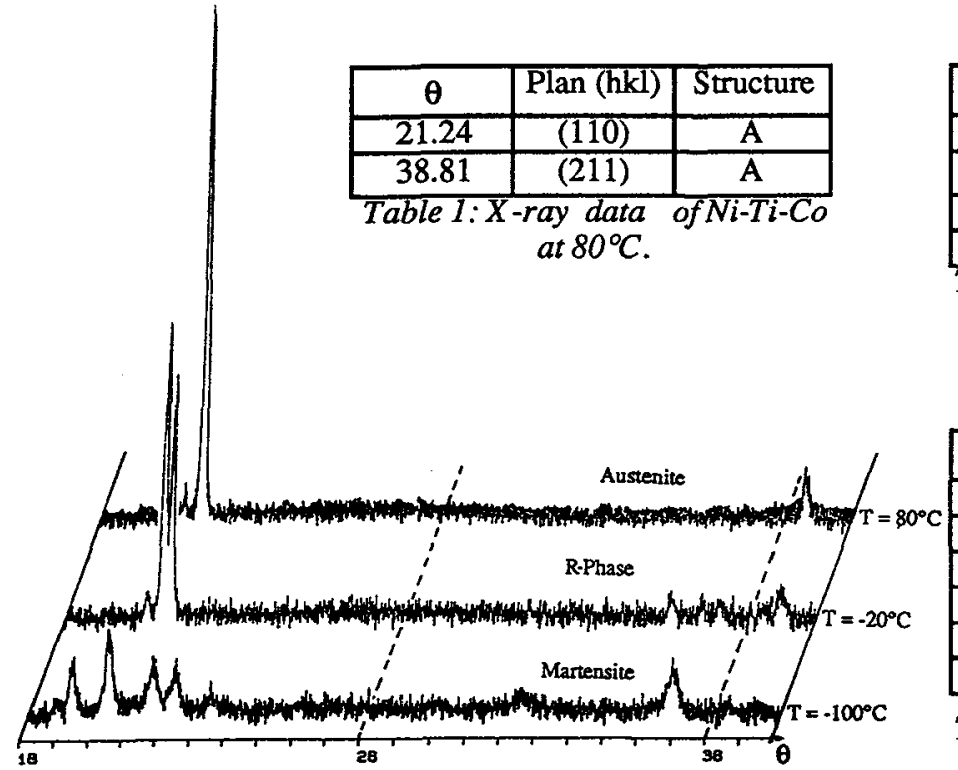

\begin{tabular}{|c|c|c|}
\hline$\theta$ & Plan (hkl) & Structure \\
\hline 19.57 & $(002)$ & $\mathrm{M}$ \\
\hline 20.64 & $(11 \overline{1})$ & $\mathrm{M}$ \\
\hline 21.96 & $(020)$ & $\mathrm{M}$ \\
\hline 22.57 & $(111)$ & $\mathrm{M}$ \\
\hline Table 2 :X-ray data of Ni-Ti-Co \\
at -100 ${ }^{\circ} \mathrm{C}$.
\end{tabular}

Figure 3 : X-ray spectra of Ni-Ti-Co, on cooling.

The results can be summarised as follows.

- Ni-Ti-Co : Experimental results on X-ray diffraction, on heating, show two transformations in the temperature range corresponding to the unique peak of DSC :

$*$ at $-100^{\circ} \mathrm{C}$, the alloy is fully martensitic ;

$*$ at $0^{\circ} \mathrm{C}$, it consists of two phases, martensite and R-phase (Table 4, Fig. 4) ;

$*$ at $25^{\circ} \mathrm{C}$, it consists of two phases, R-phase and austenite (Table 5, Fig.4);

$*$ at $60^{\circ} \mathrm{C}$, the alloy is fully austenitic.

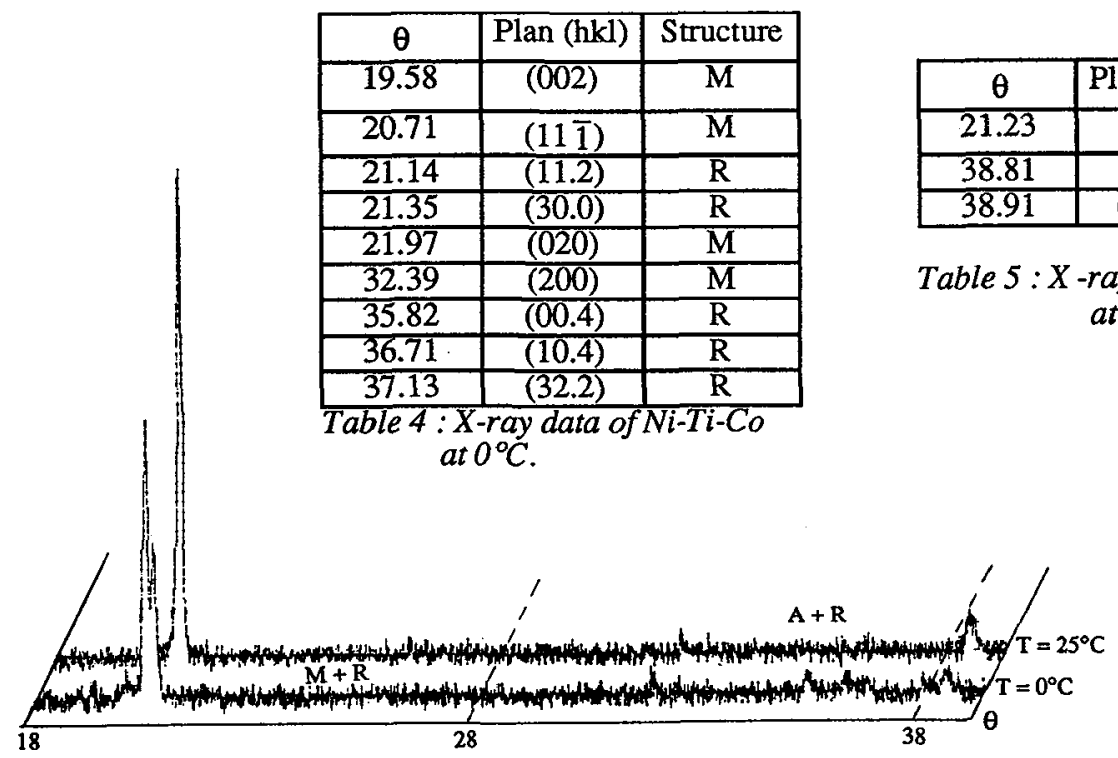

Figure 4 : X-ray spectra of Ni-Ti-Co, on heating. 
- NiTi :

* at $-20^{\circ} \mathrm{C}$, the alloy is fully martensitic ;

* at $63^{\circ} \mathrm{C}$, it consists of martensitic and austenitic phases (Table 6, Fig. 5) ;

$*$ at $90^{\circ} \mathrm{C}$, it is fully austenitic.

\begin{tabular}{|c|c|c|}
\hline$\theta$ & Plan (hk1) & Structure \\
\hline 19.64 & $(002)$ & $\mathrm{M}$ \\
\hline 20.67 & $(11 \overline{1})$ & $\mathrm{M}$ \\
\hline 21.25 & $(110)$ & $\mathrm{A}$ \\
\hline 21.91 & $(020)$ & $\mathrm{M}$ \\
\hline 22.50 & $(111)$ & $\mathrm{M}$ \\
\hline
\end{tabular}

\begin{tabular}{|c|c|c|}
\hline$\theta$ & Plan (hkl) & Structure \\
\hline 23.76 & $(1 \overline{2} 0)$ & M \\
\hline 32.37 & $(200)$ & M \\
\hline 36.76 & $(2 \overline{2} 0)$ & M \\
\hline 38.85 & $(211)$ & A \\
\hline
\end{tabular}

Table 6 : X-ray data of NiTi at $63^{\circ} \mathrm{C}$.

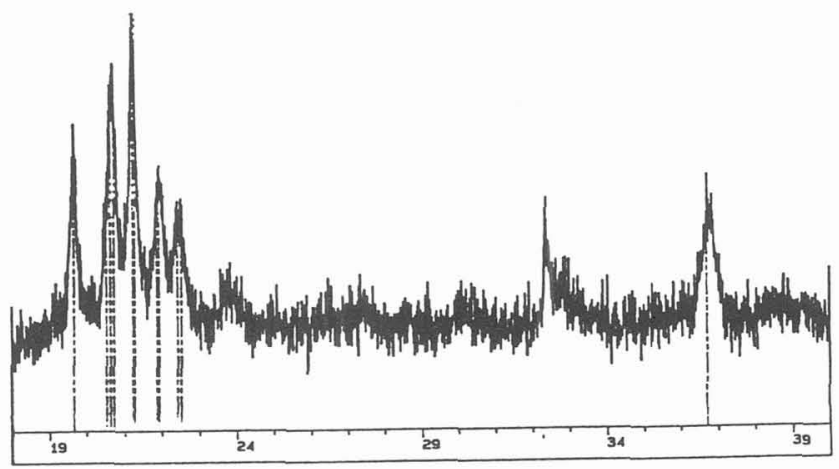

Figure 5 : X-ray spectra of NiTi, on heating, at $63^{\circ} \mathrm{C}$.

No R-phase could be detected at any temperature during the heating cycle following a complete cooling cycle.

\section{DISCUSSION}

A schematic free energy evolution analysis can help us in understanding the thermomechanical stabilisation induced by cycling. This is due to a large increase in the dislocation density of the specimen. These dislocations are maintained in austenite and martensite and they increase the free energy of the two phases. This increase is however larger in the martensitic state (the Burgers vectors are larger in the martensite than in the austenite).

The $\mathrm{A} \rightarrow \mathrm{R}$ transformation is not sensitive to the cycling. The lattice distortion associated with this transformation being very small, the increase in the dislocation density does not practically affect the process.

It is also evident from the results presented, that on cooling bulk as well as the melt spun alloys, the austenite first transforms to the R-phase which then transforms at lower temperatures to martensite. The situation with the heating is not so clear. Both bulk as well as melt spun Ni-Ti-Co alloys, on the strength of either two clearly observable peaks on heating in the DSC or the characteristic modulus decrease associated with the transformation involving $R$-phase generation or the existence of martesite, $R$ and austenite phases as confirmed by XRD results on heating, can be considered to exhibit the martensite $\rightarrow R$ and subsequently the $\mathrm{R} \rightarrow$ austenite transformations. In NiTi, where similar observations on heating, 
however, are absent, the martensite should be considered to retransform directly to austenite. This discrepancy would be attributed to the extent of separation of the two transformations on cooling.

There is an alternative explanation to the observed behaviour without the need to invoke two separate retransformation paths in the two systems. Such an explanation is based on the premise that the driving force for the transformation martensite $\rightarrow$ austenite is always greater than the driving force for the martensite $\rightarrow$ R-phase transformation. The former would thus be preferred over the latter transformation. However, in Ni-Ti-Co alloys, the retransformed austenite, since it finds itself at a temperature where the R-phase is still stable relative to the austenite, would immediatly transform to the R-phase. So, the first and lower temperture peak on heating is to be attributed to a double transformation, the martensite to austenite which is endothermic, the austenite transforming as it forms to R-phase, this reaction being exothermic. This would account for the net heat content of that peak being nearly the same as that of the R-phase $\rightarrow$ martensite transformation on cooling. Subsequently, at a higher temperature, the R-phase transforms to austenite that gives rise to the second DSC peak on heating. In the case of NiTi alloys, since the temperature martensite $\rightarrow$ austenite transformation itself occurs at a temperature above the region of stability of the R-phase, the austenite once formed will not transform to the R-phase. The heat content of this peak will thus be larger than the heat content of the R-phase $\rightarrow$ martensite transformation, the difference being that of the austenite $\rightarrow$ R-phase transformation. This hypothesis would pose an experimental challenge to be confirmed. In the meantime, it would be worthwhile considering it for its strength ad weaknesses.

Acknowledgment

The authors thank Miss C. Gallis for experimental results on X-ray diffraction on temperature.

\section{REFERENCES}

1. JORDAN (L.), MASSE (M.), COLLIER (J.Y.) and BOUQUET (G.). - Etude comparative des évolutions structurales intervenant dans les alliages à mémoire de forme de type NiTi et Ni-Ti-Co.J. Phys. C3. 1994, 4 : 157-162.

2. JORDAN (L.), MASSE (M.), COLLIER (J.Y.) and BOUQUET (G.). - Effects of thermal and thermomechanical cycling on the phase transformations in NiTi and Ni-Ti-Co shape memory alloys. Journal of Alloy and Compounds. 1994 (to be published).

3. OTSUKA (K.). - Introduction to the R-phase transition in "Engineering Aspects of Shape Memory Alloys". DUERING (T.W.), MELTON (K.N.), STOCKEL (D.) and WAYMAN (C.M.), Eds Butterworth-Heineman. $1990: 36-45$.

4. STACHOWIAK G.B.) and McCORMICK (P.G.). - Shape memory behaviour associated with the R and martensitic transformations in a NiTi alloy. Acta Metall. 1988, 36(2) : 291-297.

5. MERCIER (O.), TIRBONOD (B.) and TOROK (E.). - The internal friction spectrum of premartensitic transformation. J. Phys. C5. 1981, 42(10) : 1037-1042.

6. GOO (E.) and SINCLAIR (R.). - The B2 to R transformation in $\mathrm{Ti}_{50} \mathrm{Ni}_{47} \mathrm{Fe}_{3}$ and $\mathrm{Ti}_{49.5} \mathrm{Ni}_{50.5}$ alloys. Acta Metall. 1985, 33(9) : 1717-1723. 